practice, we are assured, has already resulted in a very marked diminution of the schools of fish in that vicinity, and has been greatly resented by the people of the State, who are endeavouring to drive the operator from its waters.

AN earthquake at Arequipa in Peru, on the 2Ist December, was strong, and is said to have lasted fifty or sixty seconds. It was attended with much subterranean noise.

AN earthquake shock was felt at Bombay and as far north as Baroda on the night of January $3 \mathrm{r}$. It was distinctly noticed over a large area, but did little or no damage.

RECENT telegraphic advices from Havana announce that Captain Selfridge, who is engaged in prosecuting the Darien ship-canal exploration, thinks he has discovered a practicable oute over a line where the elevation of the divide is not more than three hundred feet above the level of the sea. The despatch is dated Paya, on the Tuira River, a stream which empties into the Gulf of San Miguel, on the Pacific.

The well-known Pinang or Betel nuts, the seeds of Areca catcchu, a handsome palm cultivated in all the warmer parts of Asia, and used by the natives to chew with lime for the purpose of producing a gentle kind of intoxication, form an important article in the interior trade of the Malayan Archipelago, being exported from Sumatra to other islands in large quantities. The exports from Padang alone in one year amounted to 5,057 pieuls.

From the twenty-sixtl Report of the Proceedings of the Calcutta School-Book Society, we learn that during the two years 1868-1869, more than 179,300 rupees was spent in purchases of books for distribution among the natives, the object of the society being "to supply and distribute, at the lowest possible price, a healthy household literature in the vernacular tongues," in which it is assisted by a small monthly grant from Government. The titles of some of the works circulated sound to us peculiar, as "A Treatise on Spiritualism and its Manifestations," "A Drama against Upstarts," "The Grief of Females on the Departure of their Husbands by Rail on Monday," \&c. ; while the modicum of science given is very small ; and, judging from the titles, we should suppose that the instruction in natural and physical science, thought good enough for the natives of Ifindostan, is about on a par with that which prevailed in this country in the time of Oliver Goldsmith.

Tre Berwickshire Naturalists' Field Club, the oldest society of the kind in Britain, has issued its "Proceedings" for 1870 . Besides one or two archæological papers, and an address from the President, the Rev. G. S. Thomson, we have the following coutributions to Natural History and Ethnology, chiefly connected with these branches as represented in the district :- " The History of the Wolf in Scotland," "Turnip Insects during 187o," "Botanical Notices," and "Contributions to the En. tomology of the Cheviots," chiefly in coleoptera ; all these from Mr. James Hardy. The Secretary, Mr. George Tate, contributes a carefully worked-out paper on "The Stature, Bulk, and Colour of the Eyes and Hair of Native Northumbrians ; " and Mr. Ralph Carr treats of "The Northumbrians between Tyne and Tweed." There are several other short papers of local interest, and a statement of the rainfall concludes the number.

IN a discussion at the Indian Conferences at the Society of Arts, as to a proposition of Col. Wragge to employ Neilghery peat on railways, it was mentioned that the two largest peat bogs near Ootacamund have been swept away in rains. This was alleged to be through cutting them at the wrong end.

WE learn from Nicaragua that the xiver and port of San Juan dil Norte are shoaling in many places. Where there was deep water in the latter ten years ago, there is now a bank above the surface.
ON THE CONNECTION BETWEEN TERRES TRIAL TEMPERATURE AND SUN-SPOT PHENOMENA

MR. STONE, the newly-appointed Astronomer Royal $\mathrm{I}$ at the Cape of Good Hope, has recently communicated to the Royal Society an important paper and curve, in which the thermometric observations taken there since I 84I are discussed. This curve he has compared with another constructed on Wolf's observations of sun-spots, and with the following result, which we give in his own words :-

"The agreement between the curves appears to me so close that I cannot but believe that the same cause which leads to an excess of mean annual temperature leads equally to a dissipation of solar spots. There is on the whole a curious appearance of logging of the inverse curve of solar spots over that of temperature. At the maximum about 1856, this, however, does not appear to be the case ; but when the uncertainties of the data, both of the solar spots near the minimum, and of the mean temperature also, are taken into account, such discrepancies might perhaps fairly be expected, even if there be a physical connection between the two phenomena as results of some common cause. If there be a sensible inequality in the mean temperature with a period of about ten years, then the mean temperature resulting from the observations in the temporary observatory, which were made near a maximum, will be tos high. The corresponding ordinates, therefore, will be depressed too much relatively to those corresponding to observations made in the other two observatories. In the curve 2 I have imperfectly corrected the mean of the results for the temporary observatory on the supposition of such an inequality existing. The only result of such a correction is to modify the curve at the points of junction of the observations made in different positions. The general form is unaltered. It should be mentioned that the point about which the curves appear to differ most is near or at the change of exposure from the original observatory to the temporary shed about I 852 .

"I may mention that I had not the slightest expectation, on first laying down the curves, of any sensible agreement resulting, but that I now consider the agreement too close to be a matter of chance. I should, however, rather lean to the opinion that the connection between the variation of mean temperature and the appearance of solar spots is indirect rather than direct, that each results from some general change of solar energy. . . . . The problems of meteorology appear to be presented here in a simpler form than in England, and probably systematic photographic self-registering observations extended over a few years might lead to important results."

\section{EXPERIMENTS ON CERTAIN VIBRATORY PHENOMENA}

$T H E$ apparatus made use of consists simply of a cardboard disc furnished with radial slits, and which can be rotated with any desired velocity. To examine a coal-gas flame singing in a glass tube, the disc is placed in front of the flame, and the eye placed where the slits pass in a vertical position. When the dish rotates with such a velocity that the interval between two slits passing the eye is just equal to the period of a complete vibration of the flame, the flame appears to be motionless; but if the velocity of the disc be slightly reduced, the flame is seen slowly to go through its changes of form, appearing to consist of a series of puffs, resembling those from the funnel of a luggage locomotive. When the interval between the passing of the slits is equal to, or is one-half, one-third, \&c., of the period of vibration of the flame, a singular appearance of a phantom disc is seen, having as many or twice or three times the number of slits really in 
the disc; this phantom wheel appears motionless if the periods exactly coincide, but if they do not, it slowly revolves in one direction or the other. It is obvious that this affords an easy method of counting the vibrations of the flame. With a sixteen inch tube I thus found the number of complete vibrations per second to be about 453.

When the disc is rotated in front of a vertical vibrating wire, the eye being placed where the slits pass in a horizontal position, the interval of the slits passing being equal to a complete vibration of the wire, the wire appears thrown into undulations and motionless. If the periods do not exactly coincide, the undulations travel up or down the wire. If the velocity of the disc be doubled, or trebled, the apparent number of wires is increased in like proportion; and if it be regarded by the two eyes placed where the slits do not pass in a horizontal position, they assume the form of spirals, which appear to revolve around each other in an extremely beautiful and illusive manner. In the above cases I have supposed the wire to be twanged in the centre, in which case the undulations are beautifully symmetrical curves, and represent a pure note. If, however, the wire be twanged near to one end, the change in the quality of the note is manifest, the irregularity of the curves showing the presence of minor undulations superimposed upon the primary one. The best wire for this' purpose is a fine spiral one, as it gives vibrations of great amplitude, and of long continuance. A vibrating steel rod also appears thrown into the same undulations. CHARLES J. WATSON

\section{THE ACTION OF FLUORSPAR ON DIFFERENT} QUALITIES OF CAST IRON

IN my articles contributed to NatURE (No. 57, p. 94 , and No. 6.1, p. 233), I have given descriptions of my process of applying fluorspar combined with oxides, and fluorspar combined with oxides containing titanium, to ordinary cast iron.

It is reported that attempts have been made to apply fluorspar alone to ordinary cast iron by eminent chemists in the laboratory, but the results have been of a negative character. These reports have been corroborated by my own experiments. I have discovered, " however, that although fluorspar has no effect when used alone in treating ordinary cast iron, it will act energetically upon cast iron containing titanium. The titaniferous cast iron was made at Glassdale Furnaces, near Whitby, by melting Cleveland white pig iron in a cupola in admixture with Norwegian titanic iron ore, and blast furnace cinder as a flux. This metal was treated here in the laboratory by being melted upon powdered fluorspar. The resulting metal was found to be wruaght iron.

These results may be obtained in any suitable vessel, furnace, apparatus, or process; the only conditions necessary to be observer are, that the metal be maintained in the fluid state, and the fiuorspar placed so as to act upon the metal from the under side upwards, or placed in admixture with it, and that when apparatus is used having silicious linings, the silicious linings be protected with sheet or cast iron placed upon the silicious lining before the fluorspar and iron to be treated are charged into the vessels. No labour is necessary, except that of "balling" the metal, and removing it from the apparatus.

The results given by this experiment go to prove that by this process superior qualities of whought iron, which will be purer than the highest standard brands of wrought iron, may be produced from the English Cleveland pig iron, which contains, accurding to the best metallurgical authorities, from $I \cdot 25$ to $I \cdot 38$ per cent. of phosphorus.

One ton of Clevelund pig iron was melted in a cupola with $7 \mathrm{cwts}$. of Norwegian titanic iron ore, containing, by analysis, about 40 per cent. of titanic acid. The resulting metal was titaniferous cast iron, analysing :-

$$
\begin{aligned}
& \text { Titanium . . . . } 1255 \mathrm{I}
\end{aligned}
$$

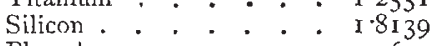

$$
\begin{aligned}
& \text { Phosphorus : . . . . } 04664 \\
& \text { Sulphur. . . . . . } 03620 \\
& \begin{array}{l}
\text { Sulphur. } \\
\text { Carbon . }
\end{array} \\
& \text { * Patent No. 318, Feb. 3, 187o }
\end{aligned}
$$

Hence it appears that the iron, by being re-melted with titaniferous iron ore, took up $1 \cdot 25$ per cent. of titanium, and lost 0.90 per cent. of phosphorus, and $x .75$ per cent. of carbon. It is obvious that the metal in this condition is not available for any purpose without subsequent treatment, as it contains about as great an amount of impurities as it did before treatment.

The advantages gained by re-melting the pig iron with tita. niferous iron ore are, a reduction of the amount of phosphorus and carbon, and the alloying of the metal with titanium, which facilitates the removal of the impurities in the subsequent treatment.

The above described titaniferous cast iron was remelted upon fluorspar, and about 30 minutes after the irom melted, or in about an hour after they were both charged, the iron was found to be malleable iron; the button analysing as follows :-

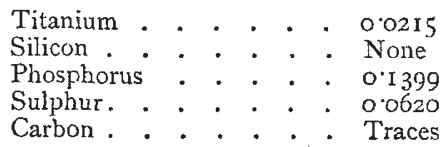

When worked on a larger scale, so as to produce blooms that can be worked into merchantable shapes, the finished results will show less phosphorus and sulphur than the above analysis, as it is well known to metallurgists, by the experiments of Messrs. Calvert and Johnson, published in full in Kerl's "Metallurgy," vol. ii., "Copper and Iron," 1869 , that 0.022 per cent. of phos. phorus, and 0.040 per cent. of sulphur, are removed in working blooms into finished iron.

It will be seen that the action of the fluorspar removed 49662 per cent. of the impurities contained; and that the resulting metal contains less impurities in amolint than the highest standard qualities of wrought iron. The explanation of these effects I leave to chemical investigators, without hazarding an opinion which might be erroneous, and therefore disadvan. tageous to me.

JAMES HENDERSON

\section{MR. WALLACE'S ANNIVERSARY ADDRESS*}

A CONSIDERABLE portion of this Address is devoted to a discussion of the facts of distribution of beetles, as presented by Mr. Wollaston in his great work, the "Insecta Maderensia," with special reference to the views advocated by Mr. Andrew Murray, in his paper on the Geographical Distribution of Beetles. After touching on the various methods by which insects are known to be distributed, and mentioning several of the instances in which they have been captured some hundreds of miles from land, it is concluded that, in opposition to the view held by $\mathrm{Mr}$. Murray, there is no reason to believe that the Atlantic islands owe their Coleoptera to a former land connection with the continent, more especially as there is such strong evidence against that view in the total absence of mammals and reptiles. $\mathrm{Mr}$. Wailace then applies Mr. Wollaston's facts to a detailed test of these views; and, as this portion of the paper is of general interest to naturalists, we give it at length :-

The most novel and striking facts brought out by Mr. Wollaston's researches in Madeira are, as is well known (I) the affinity with the Mediterranean fama; (2) the total absence of certain large divisions of Coleoptera abundant in that fauna; (3) the number of new and peculiar species and of new and anomalous genera; and (4) the unexampled preponderance of apterous species. Now accepting, as Mr. Murray does, the theory of slow change of forms by natural causes, we may take the first and third of these facts as proving that the origin of the Madeiran fauna is of very ancient date. Let us see, therefore, how the second and the fourth set of facts bear upon the mode of its origin, whether by a land-connection with Europe or by transmission across the sea. It will be convenient to take first the facts presented by the apterous or winged condition of the species.

This striking peculiarity consists, either in species being apterous in Madeira which are winged elsewhere, or in genera which are usually winged consisting of only apterous species in Madeira, or lastly, in the presence of endemic apterous genera, some of which have winged allies, while others belong to groups

* An Address read at the Anniversary Mefting of the Entomological Society of London, on the 23 rd of January, 187c, by Alfred R. Wallace, F.Z.S., F.R.G.S., President. 